\title{
Familial Neuroblastoma
}

National Cancer Institute

\section{Source}

National Cancer Institute. Familial Neuroblastoma. NCI Thesaurus. Code C115225.

Neuroblastoma inherited from a parent and caused by mutations in the ALK or PHOX2B genes. Familial neuroblastomas have a higher incidence of multiple primary tumors and are diagnosed at an earlier age. 